\title{
Contribuições de projeto de extensão à formação inicial em curso de Pedagogia em universidade pública
}

\author{
Extension project contributions to initial training in Pedagogy course at public university
}

Andreia Cristiane Silva Wiezze"

\section{Resumo}

Este artigo apresenta reflexões em torno da concepção, da execução e da avaliação de um projeto de extensão universitária desenvolvido no âmbito do programa Núcleos de Ensino da Universidade Estadual Paulista, no período de 2009 a 2016. O texto está organizado em quatro seções: a primeira apresenta, em linhas gerais, o programa Núcleo de Ensino; a segunda destaca a concepção, as bases teórico-metodológicas e o procedimento do projeto de extensão; a terceira seção aponta os resultados gerais obtidos sobre a população atendida, no caso, crianças com dificuldades nas relações interpessoais na escola; e a quarta traz a repercussão à formação dos universitários do curso de licenciatura envolvidos no trabalho. Conclui-se, a partir deste projeto, que a extensão universitária, em sua articulação com o ensino e a pesquisa, oportunizou formação diversificada e ampla aos alunos universitários, além de impactar na realidade das crianças participantes do projeto nas escolas públicas envolvidas. Diante desses resultados, fazem-se necessários aprofundar as discussões e ampliar essas práticas nos cursos de graduação.

Palavras-chave: Formação de professores. Projeto de extensão. Universidade pública.

\section{Abstract}

This article shows reflections about conception, execution and avaliation of a university extension project developed within the Program Nucleus of Education at the State University of São Paulo (Unesp), from 2009 to 2016. The text is organized in four sections: the first presents, in general lines, the Program Nucleus of Education; the second emphasizes the conception, theoretical-methodological bases and the extension project procedure. The third section points the general results obtained on the population assisted, in the case, children with difficulties interpersonal relationships in the school. And the fourth brings the repercussion of this extension project in the formation of these degree students. Hereby this project, we concluded the university extension, in its articulation with teaching and research, provided a diversified and wide formation to university students, as well as impact on the reality of the participated children in the project in the public schools involved. Based on the results, it is necessary to deepen the discussion and extended these practices in degree courses.

Keywords: Extension project. Public university. Teacher formation.

Recebido em 31/03/2018 - Aprovado em 13/06/2018

http://dx.doi.org/10.5335/rep.v25i3.8576

Doutora em Educação pela Universidade Estadual Paulista Júlio de Mesquita Filho. Docente do Departamento de Educação, na área de Psicologia da Educação, na mesma instituição, campus de Presidente Prudente, São Paulo. E-mail: andreia.wiezzel@unesp.br 


\section{Núcleos de Ensino: compromisso com o ensino público}

O programa Núcleos de Ensino da Universidade Estadual Paulista (Unesp) foi criado na década de 1990 com o objetivo de melhorar o sistema público de ensino por meio da articulação de ações entre escola e universidade. À época, tal programa constituiu uma inovação, diante da perspectiva do tripé ensino, pesquisa e extensão atribuído às universidades públicas. O programa rapidamente se espalhou, de forma que, em 2017, houve 117 projetos aprovados em 14 unidades universitárias, dentro de um orçamento de $\mathrm{R} \$ 888.144,74$ (oitocentos e oitenta e oito mil, centro e quarenta e quatro reais e setenta e quatro centavos).

Os objetivos do programa foram sendo aprimorados, primando, entre outros aspectos, pela articulação entre extensão, ensino e pesquisa:

1- Promover a parceria entre a Universidade e a escola pública; 2- Incentivar o ensino e a pesquisa de caráter disciplinar ou interdisciplinar nas unidades de Educação Infantil, Fundamental e Médio do Sistema Público de Ensino; 3- Promover ações educativas e inclusivas junto aos movimentos sociais; 4- Apoiar a produção de material didático-pedagógico; 5- Contribuir com os processos de formação inicial dos graduandos da Unesp e de formação continuada dos professores da rede pública de ensino (UNIVERSIDADE ESTADUAL PAULISTA, 2016, p. 1).

Os projetos abrangem as áreas de: 1- Processos de ensino, de aprendizagem dos componentes curriculares; 2- Metodologias do ensino inovadoras; 3- Produção de materiais didáticos inovadores; 4- Tecnologias de informação e comunicação nos processos educacionais; 5- Estrutura, gestão e relações humanas na escola; 6- Elementos históricos e culturais brasileiros; e 7- Educação inclusiva. Em cada uma dessas sete áreas, há a especificação de temas que interessam ao programa, mas que não são abordados neste trabalho, porque ultrapassam as dimensões propostas.

Em 2018, há 200 bolsistas trabalhando nas referidas áreas sob orientação dos docentes universitários em escolas da educação básica públicas. A gestão desses projetos se dá por um núcleo regional, localizado em cada unidade universitária, tendo sua ação referendada em termos orçamentários e estatutários pela Reitoria da Unesp. Os gestores são eleitos na própria unidade universitária, sendo um coordenador e um vice-coordenador. $O$ critério para a participação na eleição é a coordenação de projeto no âmbito do Núcleo de Ensino da unidade, em ano anterior ao da eleição.

Os gestores organizam todo o processo seletivo dos projetos, realizam reuniões entre os coordenadores de projetos, garantem o cumprimento dos projetos dentro dos prazos, encaminham projetos, relatórios e solicitações à Pró-Reitoria de Graduação e, por vezes, organizam eventos de extensão. 
O desenvolvimento dos projetos nas escolas, conforme o Estatuto dos Núcleos Regionais de Ensino da Unesp (UNIVERSIDADE ESTADUAL PAULISTA, 2008), permite a realização de um levantamento das condições de ensino e aprendizagem nas escolas e das necessidades formativas dos professores, o que orienta não só a criação de projetos específicos para dirimir as dificuldades encontradas como também o redirecionamento dos cursos de formação inicial e continuada de professores na universidade. Nesse contexto, destaca-se que o campus em que o projeto de extensão a ser apresentado é desenvolvido abrange seis cursos de licenciatura, a saber: Educação Física, Física, Geografia, Matemática, Pedagogia e Química. Diante disso, é notória a relevância desses projetos para inserção da academia na realidade das escolas públicas como forma de atualizar seus cursos, como fica patente no item 3 das Normas Orientadoras dos Núcleos de Ensino: "Divulgação dos resultados dessas pesquisas nos Conselhos de Curso, como subsídio para a análise crítica dos conteúdos e ações didático-pedagógicas de disciplinas" (UNIVERSIDADE ESTADUAL PAULISTA, 2005, p. 4).

Esta articulação é muito importante, tendo em vista que, por conta do contrato de trabalho, não é possível à maioria dos docentes universitários estar presente nas escolas públicas como profissionais, para acompanhar as transformações pelas quais a educação tem passado. Sabe-se que a educação tem sofrido muitos desafios, que as dificuldades estão muito complexas, e que os projetos de extensão seriam um meio de se ter contato com essa realidade. Por via deles, é possível dar voz às crianças, aos professores, aos pais, aos gestores, enfim, criar uma interlocução, para que a academia não trabalhe com base em experiências desatualizadas, assim como procedia em um passado muito recente.

Por meio do contato com as escolas, é possível redefinir projetos de pesquisa e extensão, ganhar tempo, investir nos pontos mais críticos, auxiliar na formação dos profissionais em serviço, atuando não apenas em pontos deficitários de sua formação, como também na atualização de pontos que se façam necessários diante das transformações que a educação tem passado. Em um aspecto mais amplo, resgatando-se novamente as normas orientadoras dos Núcleos de Ensino, pode-se até mesmo pensar em políticas públicas, tendo em conta a dimensão que o trabalho em extensão pode tomar:

Revisão de dados obtidos, sistematizando-os, de modo a constituir tanto um referencial para ações didático-pedagógicas para o Sistema Educacional, quanto um referencial teórico, passível de subsidiar propostas pedagógicas significativas para políticas educacionais (UNIVERSIDADE ESTADUAL PAULISTA, 2005, p. 4).

Ao final do desenvolvimento do projeto, é encaminhado um relatório à coordenação local. No relatório, deve constar as ações desenvolvidas, os trabalhos dos 
bolsistas, os resultados obtidos, os eventos nos quais coordenadores de projetos e bolsistas participaram e, ainda, as publicações decorrentes do projeto. Dois meses após o encerramento do projeto, os coordenadores encaminham, ainda, um capítulo de livro, escrito em coautoria com os bolsistas, acerca da experiência vivida. Depois de análise realizada por pareceristas, tal capítulo pode ser publicado em livro eletrônico editado pela universidade. ${ }^{1}$

\section{Projeto de extensão Crianças Tímidas e Agressivas na Escola: investigação e intervenção por meio do lúdico}

O objeto de estudo deste projeto de extensão foi delimitado na própria sala de aula, durante as aulas de Psicologia da Educação no curso de Pedagogia. Muitos alunos do curso, que já realizavam estágios remunerados ou curriculares em escolas, traziam para as discussões temas relacionados às relações interpessoais na sala de aula, particularmente questões envolvendo mordidas, brigas, agressões, apatia, timidez. Considerando a possível adesão que um projeto de extensão nessa área teria, investiu-se na criação de um grupo de estudos que, no primeiro ano, funcionou como um projeto-piloto, com a participação de 18 alunos voluntários.

No segundo ano, após submissão ao comitê de ética, o projeto final foi encaminhado ao processo seletivo do Núcleo de Ensino. Com a aprovação, o projeto já pôde ser desenvolvido com a participação de alguns bolsistas, além de alunos voluntários, que recebiam certificados vinculados ao Programa de Formação Complementar, um tipo de formalização para atividades extraclasse que envolvem extensão ou iniciação científica. A partir de 2009, quando o projeto obteve as duas primeiras bolsas, o trabalho se desenvolveu muito, pois a universidade investiu significativamente no programa Núcleo de Ensino nos anos subsequentes. Havia todas as condições materiais e humanas, pois era oferecido, dentro de um limite, até verba para material de consumo.

O projeto, inicialmente, foi desenvolvido em apenas uma escola pública, que atendia por volta de 120 crianças entre quatro e seis anos de idade. A escola foi escolhida porque os gestores manifestaram interesse, e a localização permitia acesso facilitado à maioria dos estudantes.

O objetivo geral do projeto consistiu em investigar e realizar intervenção com crianças que, do ponto de vista dos professores, apresentassem dificuldades de relacionamento na escola, sobretudo, timidez ou manifestações agressivas que fossem muito acentuadas para a faixa etária. Os objetivos específicos envolveram: 1) identificar as características das dificuldades de relacionamento em salas de aula; 2) promover intervenção com as crianças; 3) fornecer, a partir dos dados obtidos, orientações aos professores e pais; 4) proporcionar aproximação do aluno do curso 
de Pedagogia com a realidade escolar; 5) promover a relação teoria-prática; 6) contribuir às formações inicial e continuada de professores quanto à reflexão acerca do desenvolvimento emocional da criança pequena, trabalhando a construção de relações positivas no interior da escola; e 7) consolidar a relação entre a universidade e a escola pública em um trabalho coletivo.

Do ponto de vista teórico, consideraram-se dois autores abordados na disciplina de Psicologia que faz parte da grade curricular do curso de Pedagogia: Arminda Aberastury e Donald Winnicott. Os dois autores são psicólogos, e os estudos que desenvolveram são clássicos no tema comportamento infantil. Aberastury concentrou seus estudos no sentido de conhecer profundamente as emoções infantis e, sobretudo, o acesso a elas por meio do brincar; e Winnicott investigou o desenvolvimento emocional infantil, destacando a questão da agressividade no contexto escolar, perpassando, ainda, a temática da timidez.

Essas teorias foram incorporadas à metodologia de uma pesquisa qualitativa, de tipo estudo de caso. Os dados foram coletados por meio de entrevistas semiestruturadas com pais e professores e de observações em salas de aula. As entrevistas com os pais visavam a obter elementos que permitissem reconstruir a história de vida das crianças. A intervenção com as crianças, visando a trabalhar as dificuldades de relacionamento, no sentido de amenizá-las, ocorreu por meio do brincar espontâneo, individualizado. Os encontros entre as crianças e os estagiários aconteceram uma vez por semana na brinquedoteca escolar, pelo tempo aproximado de uma hora, durante todo o ano letivo.

O brincar foi selecionado como técnica para a intervenção, pois, de acordo com os estudos de Aberastury (1992) e de Winnicott (1975), constitui atividade espontânea e privilegiada da infância. Por meio do brincar, que se encontra em um espaço intermediário entre a fantasia e o real, é possível à criança ter acesso e lidar com suas emoções, seus desconfortos, seus conflitos emocionais e situações difíceis pelas quais tenha passado ou esteja passando:

Ao brincar, a criança desloca para o exterior seus medos, angústias e problemas internos, dominando-os por meio da ação. Repete no brinquedo todas as situações excessivas para seu ego fraco e isto lhe permite, devido ao domínio sobre os objetos externos a seu alcance, tornar ativo aquilo que sofreu passivamente, modificar um final que lhe foi penoso, tolerar papéis e situações que seriam proibidas na vida real tanto interna como externamente e também repetir à vontade situações prazerosas (ABERASTURY, 1992, p. 15).

O material utilizado foi composto por brinquedos e materiais comuns, tais como bonecas, bonecos, super-heróis, carrinhos, bolas, livros de histórias, casinha em madeira, papel sulfite, lápis de cor, jogos de encaixe, panelinhas, massinha, e instrumentos musicais, disponibilizados em duas caixas de polipropileno. Os brinquedos foram selecionados com base nos estudos de Aberastury (1992) e, portanto, de acordo com a faixa etária das crianças. 
Figura 1 - Brinquedos disponibilizados às crianças

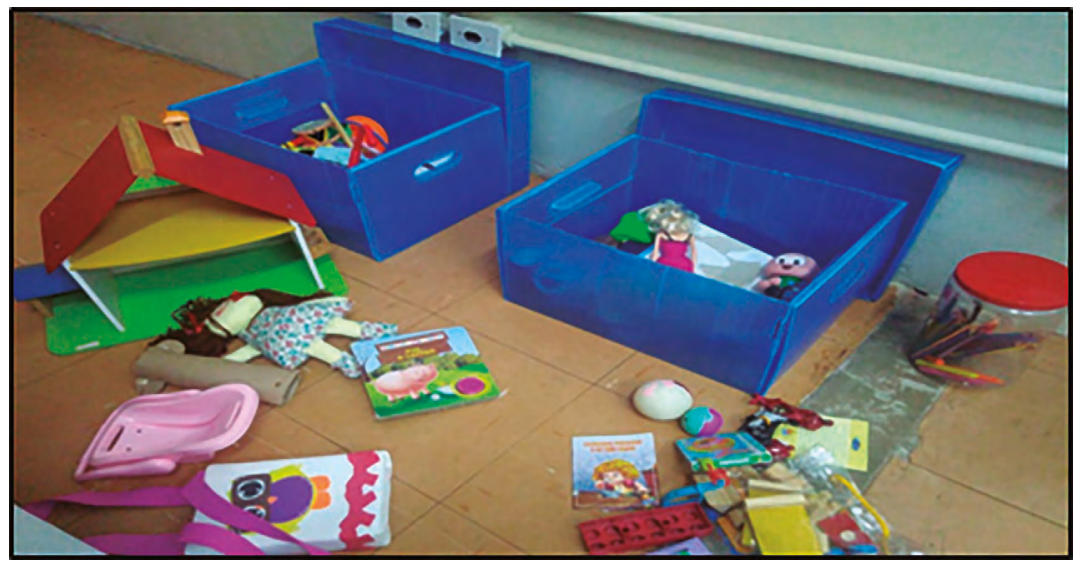

Fonte: arquivo pessoal.

As crianças podiam brincar livremente e escolher o brinquedo que desejassem. Os estagiários eram orientados a não interferir nas brincadeiras, exceto se fossem convidados a participar. Geralmente, quando eram convidados, deveriam cumprir um papel específico e muito importante no brincar de cada criança, em relação a algum aspecto de sua fantasia. Os estagiários eram orientados a estar atentos aos brinquedos que as crianças escolhiam, a forma como os manipulavam e o que verbalizavam enquanto brincavam com eles. Esses dados eram importantes para análise dos conflitos emocionais enfrentados pelas crianças e acompanhamento de sua evolução no brincar.

Figura 2 - Criança explorando a caixa de brinquedos

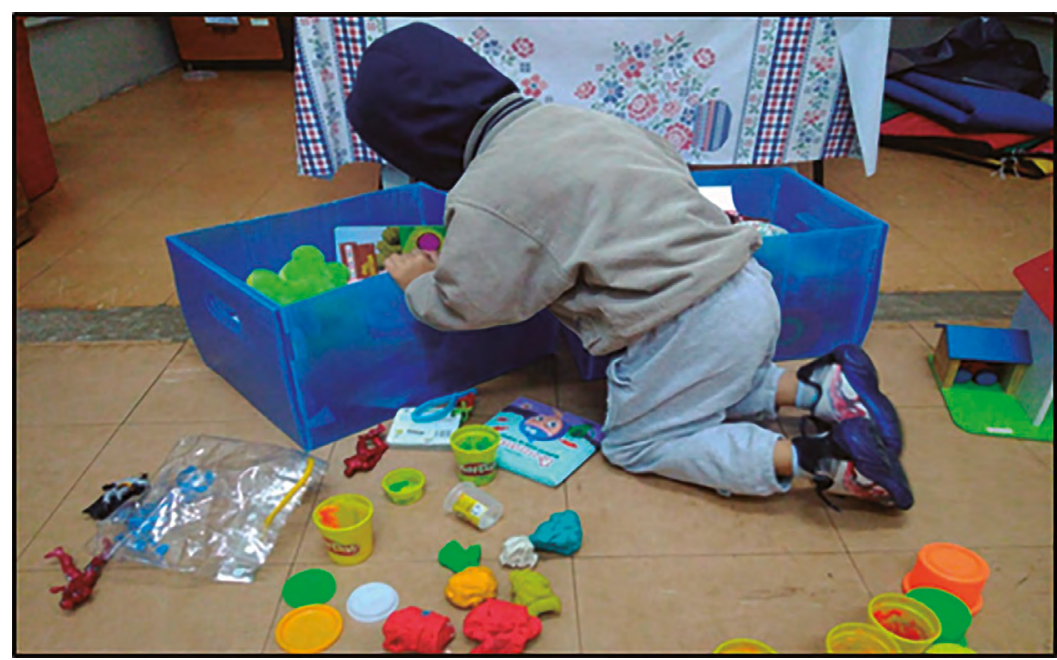

Fonte: arquivo pessoal. 
Os dados levantados foram analisados nos vários contextos e cotejados com as teorias de Aberastury (1992) e Winnicott (1975, 1982, 1983, 1992, 2001, 2005).

Sintetizando, o projeto perpassou as seguintes etapas:

1 - contato com os gestores da escola para apresentação do projeto;

2 - autorização da Secretaria da Educação do município;

3 - submissão ao Comitê de Ética em Pesquisa;

4 - reunião entre a coordenadora do projeto e os professores, durante o Horário de Trabalho Pedagógico Coletivo, para a apresentação do projeto e o levantamento dos professores que teriam alunos que se enquadrassem na proposta. Os professores que tivessem alunos que se enquadrassem no projeto e manifestassem desejo de participar eram convidados a assinar o termo de consentimento livre e esclarecido e a conceder a entrevista;

5 - reunião com os pais das crianças indicadas, para apresentação do projeto e dos estagiários que trabalhariam com as crianças. Diante do aceite, os pais assinavam ao termo de consentimento livre e esclarecido e eram entrevistados pelos estagiários;

6 - encontro entre estagiários e alunos para os primeiros contatos e observações. Cada estagiário era responsável por uma criança. Sua função era se aproximar afetivamente da criança, de forma a ser possível levá-la à brinquedoteca com tranquilidade, já que algumas, devido à pouca idade, poderiam apresentar resistência;

7 - preparo do material e do espaço da brinquedoteca;

8 - início das atividades com as crianças na brinquedoteca;

9 - orientação aos pais em reuniões bimestrais;

10 - orientação individuais aos pais em reuniões bimestrais;

11 - avaliação do projeto pelas equipes da universidade e da escola e pelos pais.

As reuniões entre a coordenadora e os estagiários ocorriam quinzenalmente, nos grupos de estudos, e eram abertas à participação de todos os interessados. Tais reuniões foram organizadas em dois momentos. No primeiro, eram realizados estudos acerca do referencial teórico do projeto e, no segundo, ocorriam as orientações gerais a respeito do trabalho a ser desenvolvido pelos estagiários. Além do grupo de estudos, havia reuniões individualizadas com os estagiários bimestralmente, para análise de cada caso e orientações específicas. A cada encontro lúdico, os estagiários acessavam o site do projeto e lançavam os relatos do dia, que eram acessados pela coordenadora para a organização das reuniões de orientação. 
Figura 3 - Equipe de estagiários em reunião com a coordenadora do projeto

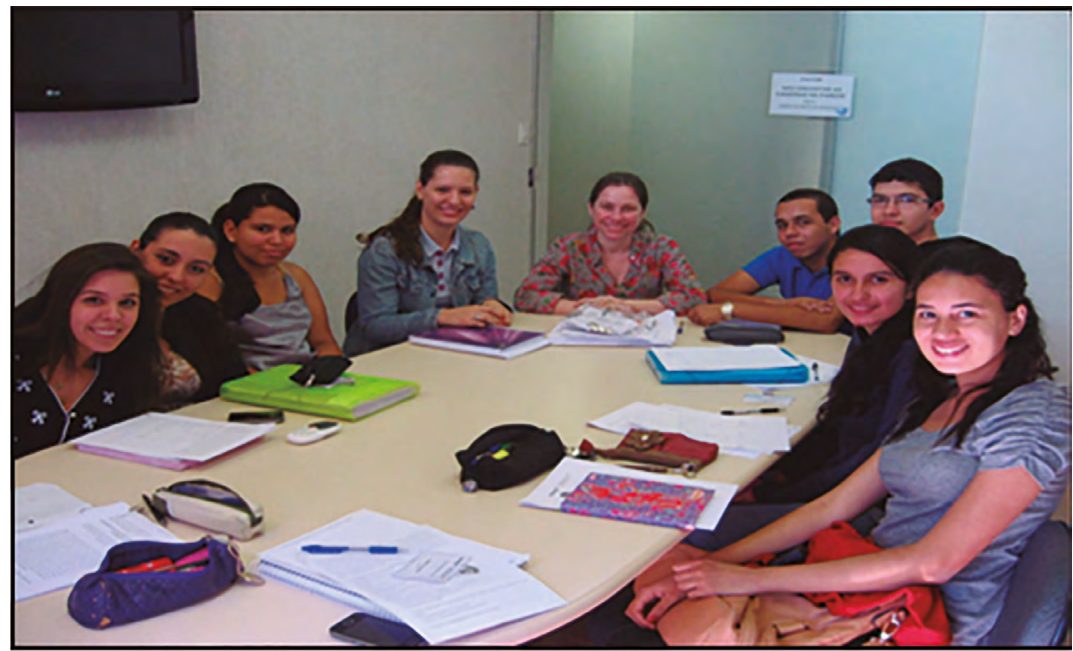

Fonte: arquivo pessoal.

O projeto, conforme já apontado, foi desenvolvido entre 2009 e 2016 e, a cada dois anos, era necessário submetê-lo ao processo seletivo do Núcleo de Ensino.

\section{Resultados}

No período em questão, passaram pelo projeto 52 estagiários do curso de Pedagogia; e, pelo Núcleo de Ensino, cerca de 15 bolsas foram concedidas. No total, três escolas foram contempladas pelo projeto, que atendeu 52 crianças. Dessas crianças, 40 apresentavam manifestações agressivas intensas em sala de aula, e 12 tinham características preocupantes relativas à timidez. Participaram 25 professores e 21 famílias das reuniões de orientação, que ocorreram bimestralmente, no período noturno.

Com relação ao tema agressividade, são expostas algumas considerações gerais acerca das crianças em forma de quadro, a partir dos dados obtidos por meio das entrevistas, observações e atividades lúdicas. 
Quadro 1 - Características gerais das crianças que manifestavam agressividade em sala de aula

1 - Houve predomínio do sexo masculino.

2 - Os alunos frequentavam a escola em período integral.

3 - Não apresentavam relações interpessoais satisfatórias com os colegas e professores.

4 - Eram briguentos, sem regras, sem limites, desobedientes, muito carentes, ciumentos, estressados, agitados, nervosos; brigavam, batiam, atrapalhavam a aula, mudavam de humor, não prestavam muita atenção na aula, deixavam de realizar as atividades propostas, às vezes pegavam coisas escondidos (termos utilizados pelos professores durante as entrevistas).

5 - Os professores, embora preocupados com o futuro desses alunos, não sabiam como ajudá-los.

6 - Esses alunos se sentiam rejeitados em casa e na escola.

7 - As demais crianças da sala de aula, por medo, interagiam pouco com eles.

8 - Os alunos que manifestavam agressividade gostavam dos professores e colegas.

9 - Desejavam ser aceitos e reconhecidos pelos familiares e pela escola.

10 - A maior parte deles passou ou estava passando por situações difíceis.

11 - Não apresentavam, necessariamente, dificuldades de aprendizagem.

12 - Não confiavam na qualidade de suas produções escolares (atividades, desenhos).

13 - As agressões físicas pareciam "sem motivo", mas sempre havia uma ou mais causas internas e/ou externas (provocações).

14 - As crianças analisadas tinham capacidade para construir, não só para destruir.

15 - Tinham dificuldades de vida e compreensão de seu lugar em seu lar.

16 - O brincar das crianças apresentava conflitos ou dificuldades emocionais decorrentes de sua idade e suas experiências (nascimento de irmãos, ciúmes da mãe, ciúmes dos irmãos, mortes de entes queridos ou dos próprios cuidadores, morte de animal de estimação, sentimento de culpa, fantasias de abandono, medo de perda do afeto, sentimentos de rejeição, dificuldades de adaptação à escola).

17 - Quando as manifestações agressivas não eram decorrentes das situações elencadas, ocorriam na esperança de obter atenção e contenção que não encontravam no lar, por motivos diversos, que escapavam ao controle das famílias.

18 - As brincadeiras evoluíram de ações puramente agressivas com brinquedos para atividades expressivas e elaborativas.

19 - Esperavam da escola um auxílio para suas dificuldades comportamentais, por isso provocavam o ambiente.

20 - As crianças começaram a se responsabilizar por seus atos agressivos, pedindo desculpas às crianças prejudicadas e tentando resolver os conflitos com diálogos, e a se envolver menos em brigas.

21 - Ao final do projeto, os professores relataram que esses alunos estavam mais comprometidos com a realização das atividades em sala de aula, estavam mais tranquilos e alegres, demonstravam preocupação em fazer as tarefas. As coisas pararam de sumir. Os alunos melhoraram com relação às regras, quando voltavam da brinquedoteca; parecia que extravasavam, sentavam, faziam a lição. Notou-se melhora em tudo, estavam mais sociáveis, os demais alunos conversavam bastante com eles, assimilavam melhor os conteúdos e prestavam mais atenção na aula, e a agressividade diminuiu.

22 - Os pais, desde o início do projeto, reconheciam que as crianças precisavam de ajuda.

23 - Os pais se importavam, mas não sabiam como resolver a situação, estavam sem forças; por isso, às vezes, ficavam inacessíveis ao diálogo.

24 - Os pais colaboraram com a pesquisa, assinaram os termos, concederam as entrevistas, expuseram suas condições de vida e confiaram suas crianças à equipe.

25 - Os pais avaliaram o projeto de forma positiva e perceberam diferença no comportamento das crianças.

Fonte: elaboração da autora. 
O trabalho de orientação dos professores das crianças perpassou três momentos. No primeiro, houve uma breve exposição do desenvolvimento emocional da criança e do desenvolvimento da agressividade e da timidez nesse contexto. O segundo momento foi marcado pela exposição e pela discussão dos dados apresentados no quadro anterior, sobretudo do item 1 ao 19. O objetivo desse trabalho com os professores foi mostrar que: 1) os professores não precisam ficar se desgastando na tentativa de localizar o motivo da agressividade da criança, pois, muito provavelmente, não o encontrarão, já que dificilmente a agressividade se explica por apenas uma única causa; 2) quando a escola ou a família entra nessa dinâmica de buscar explicações, uma instância responsabiliza a outra, e, assim, desresponsabilizam-se de auxiliar a criança; e 3) a agressividade, nessa faixa etária, não é patologia, envolve cuidado, trabalho, compreensão, acolhimento. O terceiro momento foi reservado a discussões acerca de atividades que poderiam ser desenvolvidas em sala de aula, tanto pedagógicas como relacionais, de forma a beneficiar os alunos como um todo.

Com as famílias, o trabalho foi diferenciado. As coordenadoras agendavam horários no período noturno - geralmente quando havia reuniões da escola -, para encontros entre o representante da família e a coordenadora do projeto. Durante esses encontros, predominantemente frequentados por mães, mas também por pais e avós, eram tratados assuntos diversos. Às vezes falava-se pouco da criança ou, então, falava-se dela por uma hora: os pais tinham curiosidade em saber como se comportavam na escola, se gostavam de contar experiências vividas fora da escola, tristezas e alegrias, as dificuldades dentro da escola. Ao final, faziam perguntas, tiravam dúvidas, pediam sugestões de brincadeiras para fazer com as crianças, relatavam brincadeiras e atividades que faziam com elas. Os estagiários compareciam nesses encontros para distrair as crianças que, eventualmente, os pais precisavam levar aos encontros.

Com relação às 12 crianças com características de timidez, foram levantados os seguintes dados gerais: 
Quadro 2 - Características gerais relacionadas à timidez

1 - Houve predomínio de crianças do sexo masculino.

2 - Os alunos frequentavam a escola meio período.

3 - Mostravam-se passivos, interagiam pouco com colegas, não participavam da aula, eram bem aceitos pelo grupo, não se envolviam em confusão ou brigas, quase não sorriam, falavam muito baixo, eram tranquilos, não demonstravam sentimento de raiva, eram carinhosos, choravam à toa, isolavam-se (termos utilizados pelos professores durante as entrevistas).

4 - Não despertavam preocupação nos professores.

5 - Eram bem aceitos pelos demais alunos e pelos professores.

6 - Gostavam dos professores e colegas.

7 - Os pais também apresentavam certas características de timidez.

8 - Não apresentavam dificuldades de aprendizagem, mas de participar de atividades em que tinham que se expor.

9 - Demonstravam sentir falta de contato com seus pais. O contato era limitado por motivos pessoais.

10 - Sentiam-se rejeitados pelas famílias, mas não pela escola.

11 - A maior parte desses alunos passou ou estava passando por situações difíceis (mortes, prisões, separação dos pais).

12 - Queixavam-se de dores de barriga, cólicas, que podem estar associadas à ansiedade, à tensão.

13 - Eram desconfiados e inseguros nas relações iniciais com os estagiários.

14 - Não se sentiam à vontade, inicialmente, para explorar as caixas de brinquedos.

15 - Posteriormente, esses alunos pararam de brincar, porque queriam se sentar ao lado dos estagiários para conversar, contar como tinha sido o seu dia, fazer queixas.

16 - Ao final das atividades lúdicas, não queriam retornar à sala de aula.

17 - O brincar das crianças apresentava conflitos ou dificuldades emocionais decorrentes de sua idade e suas experiências (desejo de serem fortes e corajosos, medo de uma série de fantasias decorrentes do nascimento de irmãos, medo do escuro, insegurança, medo de irmãos mais velhos, ressentimento com os pais, desejo de ter uma família, lutas entre o bem e o mal, curiosidades sexuais).

18- Os professores afirmaram que as crianças, ao final do projeto, estavam mais alegres, soltas, mais comunicativas, mais participativas.

19 - Os pais, durante as reuniões de orientação, demonstraram se preocupar com a timidez das crianças, inclusive, relacionaram alguns fatos que, segundo eles, a precederam ou a reforçavam. Pediram orientações sobre atividades e formas de interação, ressaltando que também se sentiam "meio tímidos" e, por esse motivo, não conseguiam auxiliar muito seus filhos.

Fonte: elaboração da autora.

Os conflitos que as crianças que manifestavam agressividade e timidez estavam vivenciando estavam influenciando na constituição e nos estados emocionais, refletindo em dificuldades de relacionamento em sala de aula, visto que as referências que se utilizam nas relações com as pessoas se formam nesse período, conforme Winnicott (1992).

É importante ressaltar que, nessa faixa etária, os traços de agressividade e timidez ainda não assumem caráter patológico e tampouco significam algo necessariamente ruim ao desenvolvimento da criança. Porém, sinalizam uma reação do 
organismo da criança, ainda de acordo com Winnicott $(1982,1983,1992)$, um alerta de que algo que está vivendo ou já viveu está além do que sua estrutura emocional - que está ainda em desenvolvimento - suporta. Esse é o momento em que a mente passa a utilizar os recursos que possui como forma de defesa e comunicação, restando aos profissionais da educação estarem atentos, de forma a acolherem essas crianças.

O que de fato importa é haver um trabalho entre escola e família, uma comunicação, para que ambas troquem informações e auxiliem a criança a retomar os caminhos de seus desenvolvimentos emocional e, consequentemente, social. As manifestações agressivas demandam acolhimento da criança, respeito, diálogo, estabelecimento de limites. À criança com características de timidez o mundo social deve ser apresentado aos poucos, sem a expor demais, deve-se respeitar seus limites, compreender seus medos sem julgamentos, lançar um desafio por vez. Essas crianças não podem ficar abandonadas à própria sorte dentro da instituição, para que se socializem por força dos acontecimentos, pois são alvos fáceis de outras crianças.

O projeto sempre foi bem avaliado pelos professores envolvidos, que manifestaram interesse na sua continuidade.

\section{Impacto do projeto na formação dos licenciandos de Pedagogia}

O projeto manteve estreito vínculo com a pesquisa e o ensino, como já destacado nas seções anteriores. Ao longo dos anos, vários foram seus desdobramentos nesse sentido, repercutindo sobre a formação dos alunos em vários aspectos: participação em projetos de iniciação científica com bolsa do Programa Institucional de Bolsas de Iniciação Científica (Pibic); participação em projeto do Programa de Extensão Universitária (ProExt) do Ministério da Educação - que financia instituições públicas no desenvolvimento de programas e projetos de extensão -; participação com bolsa no Programa de Extensão da Unesp (Proex); participação em eventos diversos de extensão e pesquisa; e publicações.

Egressos do curso, que participaram desse projeto, deram sequência aos estudos em nível de especialização (Universidade Estadual de Londrina) e de mestrado (Universidade Estadual Paulista, campus de Bauru). Alguns alunos estão levando a pesquisa desenvolvida no projeto para o trabalho de conclusão de curso e pretendem seguir a carreira acadêmica, como declara a aluna Helen: 
O projeto proporcionou às crianças que atendi mudanças significativas em seu estágio de timidez [...]. O desenvolvimento das mesmas ao longo dos encontros lúdicos motivou-me a utilizar os casos investigados em meu trabalho de conclusão de curso, tendo em vista os resultados conquistados [...]. Portanto, foi de grande importância a participação no projeto, pois constitui conhecimentos, experiências significativas, sensibilidade, afetividade [...]. O intuito é dar continuidade aos estudos, a fim de contribuir com as pesquisas acerca da timidez (GAIA, 2017).

No campo do ensino, o projeto tem motivado a coordenadora a ministrar palestras e minicursos e a oferecer disciplinas optativas na universidade sobre o tema. Até o momento, a coordenadora ofereceu duas disciplinas: Contribuições da Teoria Winnicottiana ao Desenvolvimento Emocional Infantil e Brinquedoteca Escolar; estando prevista uma terceira disciplina, a ser oferecida no primeiro semestre de 2019 .

Figura 4 - Aula prática de confecção de brinquedos durante a disciplina Brinquedoteca Escolar

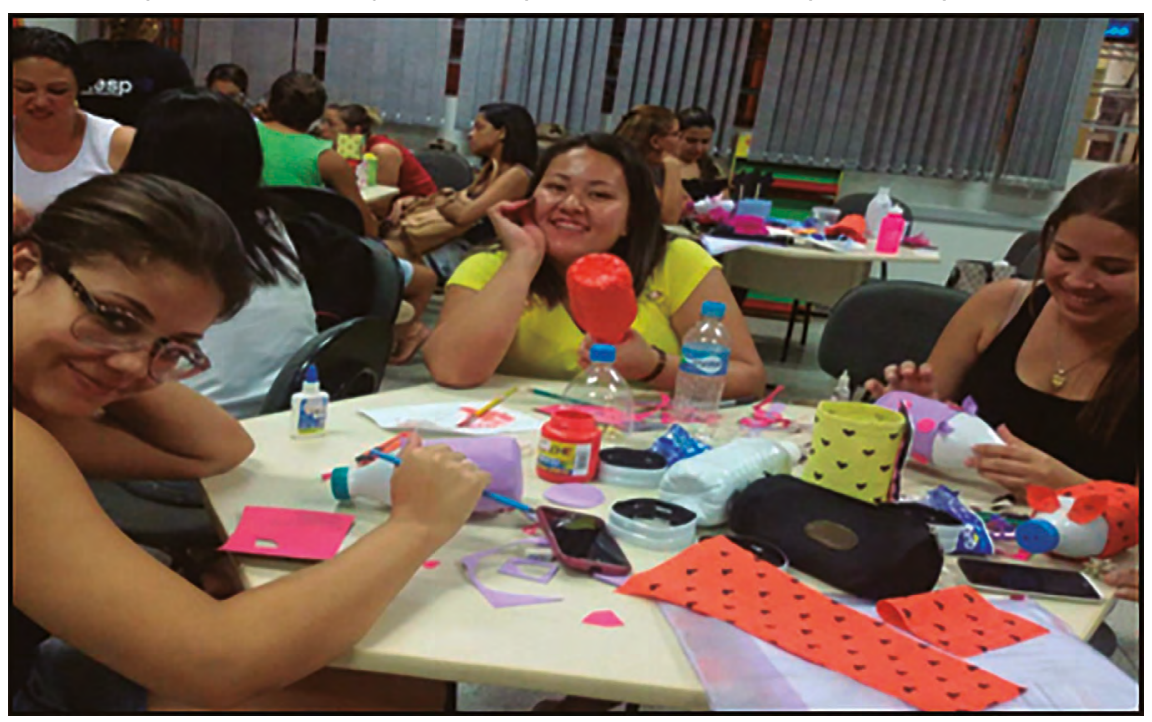

Fonte: arquivo pessoal.

Para as alunas Eliane e Michele, a participação no projeto auxiliou efetivamente na formação docente, por meio da compreensão do desenvolvimento infantil e de fatores que interferem neste desenvolvimento, encontrando formas de incluir as crianças com dificuldades nos relacionamentos: 
Ter participado da Brinquedoteca Escolar foi para mim uma experiência enriquecedora e gratificante tanto do estudo teórico como nos encontros com a criança [...]. Neste projeto, existe um apoio ao aluno, porém, ganhei muito mais ao entender melhor o universo infantil e perceber o quanto sua história interfere no seu desenvolvimento, me possibilitando uma melhor preparação para as diferenças, que certamente encontrarei na sala de aula (CARRARA, 2017).

O projeto foi importante para a minha vivência acadêmica, que é diretamente voltada à docência, e também me propiciou diversas aprendizagens através de cada experiência, dificuldades, dúvidas e desafios [...]. Dessa forma, me fez refletir sobre o direito à vida, do respeito ao próximo e às diferenças [...], sem menosprezar ou impor limites às capacidades de um ser humano. A partir das experiências adquiridas no projeto, tive a possibilidade de também refletir sobre o meu papel como futura professora e facilitadora, no sentido de que, dentro da minha sala de aula, independente da diversidade ou dificuldade, todos tenham a oportunidade e o direito de participar daquele ambiente [...]. Tive a oportunidade de vivenciar e refletir sobre os problemas relacionados a prática docente desde o início da minha formação acadêmica, com intuito de contribuir para a valorização do magistério através do incentivo à formação inicial dos futuros docentes (CARLOS, 2017).

A aluna Viviane, que trabalhou por três anos com o tema agressividade, demonstra uma compreensão mais abrangente do objeto de estudo em sala de aula:

A importância de participar do projeto se justifica pelo fato deste oportunizar adquirir conhecimento a respeito da agressividade na educação infantil [...], à medida que buscamos investigar e compreender a agressividade, como ela se origina, como se desenvolve e como se manifesta em sala de aula [...]. Também, esta experiência tem reflexos significativos em minha formação inicial [...], uma vez que, a partir do estudo e contato com a realidade das instituições de educação infantil no que se refere às manifestações agressivas neste espaço, percebi que alguns professores [...], apesar de considerarem a interferência de aspectos emocionais nos comportamentos em sala de aula, se restringem às especulações, muitas vezes, como forma velada de se desresponsabilizarem pelas crianças [...]. Diante disso, um aspecto evidenciado neste projeto é o fato de que a escola precisa representar um ambiente em que à criança seja possível um desenvolvimento integral [...], assim como nos mostram as diretrizes curriculares; portanto, as questões que envolvem as relações interpessoais - e a agressividade - precisam ser consideradas neste contexto [...]. Outro reflexo relevante à minha formação é que, como as escolas de educação infantil primam pelo desenvolvimento integral das crianças, cada vez mais precisam acolher e orientar essas crianças [...]. O que quero dizer com isso é que futuramente, ao exercer minha profissão de docente, os conhecimentos adquiridos a partir desse projeto me orientarão a lidar com tais situações [...], compreendendo e respeitando tais manifestações das crianças, ajudando-as em seu desenvolvimento integral (MANFRÉ, 2017).

A partir desses relatos, ficam claros o envolvimento dos alunos e a profundidade em termos teóricos e práticos que um projeto de extensão pode alcançar para a formação acadêmica dos alunos. 


\section{Considerações finais}

$\mathrm{O}$ artigo em questão traz algumas considerações acerca de um amplo projeto de extensão, no qual se investigaram as relações interacionais em salas de aula em educação infantil, especialmente as manifestações agressivas e de timidez. O trabalho ocorreu há alguns anos em unidades públicas de ensino de um município no interior de São Paulo.

Os objetivos do projeto, basicamente, consistiram em investigar crianças com grau considerável de manifestações agressivas e de timidez e realizar intervenção nesse contexto, tendo o respaldo de teorias da área da psicologia que pudessem contribuir para o estudo dos temas. A intervenção se deu sob a forma de atividades lúdicas com crianças e de orientações a pais e professores, visando a um melhor desenvolvimento das relações interpessoais em sala de aula. Visou, ainda, a proporcionar aos alunos universitários a relação ensino, pesquisa e extensão.

Ao longo dos oito anos de trabalho, a equipe conseguiu construir uma relação de profissionalismo e confiança com os profissionais das escolas, de forma que o ambiente educacional se tornou mais acolhedor às crianças que apresentavam dificuldades nas relações interpessoais, e o projeto de extensão passou a fazer parte do projeto pedagógico das instituições. Considera-se que o relato do caminho trilhado na construção de tal parceria seja fundamental para a reflexão sobre a relação universidade-escola.

Em âmbito geral, o projeto se mostrou plausível, tendo em vista ter contribuído na atenuação do problema, trazendo novas perspectivas aos professores, que se sentiam impotentes e estavam em busca de estratégias alternativas para trabalhar com as crianças. No decorrer dos anos, observou-se uma diminuição progressiva na quantidade de crianças indicadas pelas escolas a participar do projeto. A listagem, que inicialmente era composta por 50 crianças, no ano de 2017 , contava com apenas 7 crianças.

Nesse contexto, é interessante mencionar que os professores que participam há mais tempo do projeto não sentem mais necessidade de fazer indicações, e, por professor, a cada ano, as indicações diminuem. Isso significa que o trabalho coletivo tem feito a diferença, e que as descobertas realizadas a cada ano e socializadas com as escolas e as famílias têm sido levadas em conta de alguma forma.

Diante desses resultados, fica patente o potencial dos projetos de extensão para a formação universitária, sendo altamente relevante a troca de experiências e debates a respeito da temática. Há muito a ser feito nesta área ainda em expansão, e esta pode ser uma janela para inclusão de uma dimensão prática nos cursos de graduação, tão marcados historicamente por disciplinas que priorizam a dimensão teórica. A extensão é um passaporte, no caso dos cursos de licenciatura, para o encontro com a realidade do sistema educacional brasileiro. 
1 Essas publicações podem ser consultadas em: <https://www2.unesp.br/portal\#!/prograd/e-livros-prograd>.

\section{Referências}

ABERASTURY, A. A criança e seus jogos. 2 ed. Porto Alegre: Artmed, 1992.

CARLOS, M. da S. Entrevista concedida a Andreia Cristiane Silva Wiezzel. Presidente Prudente, 23 mar. 2017.

CARRARA, E. Entrevista concedida a Andreia Cristiane Silva Wiezzel. Presidente Prudente, 23 mar. 2017.

GAIA, H. Entrevista concedida a Andreia Cristiane Silva Wiezzel. Presidente Prudente, 24 mar. 2017.

MANFRÉ. V. B. Entrevista concedida a Andreia Cristiane Silva Wiezzel. Presidente Prudente, 23 mar. 2017.

UNIVERSIDADE ESTADUAL PAULISTA. Pró-Reitoria de Graduação. Edital dos Núcleos de Ensino da Unesp. 2016. Disponível em: <https://www2.unesp.br/portal\#!/prograd/nucleos-de-ensino17175/edital-para-2016/para-o-ano-de-2017/>. Acesso em: 28 mar. 2018.

UNIVERSIDADE ESTADUAL PAULISTA. Pró-Reitoria de Graduação. Estatuto dos Núcleos de Ensino Regionais da Unesp: estabelece as normas mínimas para criação dos Núcleos Regionais de Ensino. 2008. Disponível em: <https://www2.unesp.br/portal\#!/prograd/nucleos-de-ensino17175/coordenadores/>. Acesso em: 28 mar. 2018.

UNIVERSIDADE ESTADUAL PAULISTA. Pró-Reitoria de Graduação. Normas orientadoras dos Núcleos de Ensino. 2005. Disponível em: <https://www2.unesp.br/portal\#!/prograd/nucleos-de-ensino17175/coordenadores17178/>. Acesso em: 28 mar. 2018.

WINNICOTT, D. W. O brincar \& a realidade. Trad. José Octávio de Aguiar Abreu e Vanede Nobre. Rio de Janeiro: Imago, 1975.

. A criança e o seu mundo. 6. ed. Rio de Janeiro: Livros Técnicos e Científicos, 1982.

. O ambiente e os processos de maturação. Porto Alegre: Artmed, 1983.

. Natureza humana. Rio de Janeiro: Imago, 1992.

. A família e o desenvolvimento individual. São Paulo: Martins Fontes, 2001.

. Privação e delinqüência. 4. ed. São Paulo: Martins Fontes, 2005. 